\title{
REFINEMENT AND CROSS-VALIDATION OF NICKEL BIOAVAILABILITY IN PNEC-PRO, A REGULATORY TOOL FOR SITE-SPECIFIC RISK ASSESSMENT OF METALS IN SURFACE WATER
}

\author{
Anja J. Verschoor, ${ }^{\mathrm{a}, *}$ Martina G. ViJVer, ${ }^{\mathrm{b}}$ and Jos P.M. VinK ${ }^{\mathrm{c}}$ \\ ${ }^{a}$ National Institute for Public Health and the Environment, Bilthoven, The Netherlands \\ ${ }^{\mathrm{b}}$ Institute of Environmental Science, Leiden University, Leiden, The Netherlands \\ ${ }^{\mathrm{c}}$ Deltares, Utrecht, The Netherlands
}

(Submitted 9 June 2016; Returned for Revision 8 August 2016; Accepted 18 February 2017)

\begin{abstract}
The European Water Framework Directive prescribes that the environmental quality standards for nickel in surface waters should be based on bioavailable concentrations. Biotic ligand models (BLMs) are powerful tools to account for site-specific bioavailability within risk assessments. Several BLMs and simplified tools are available. For nickel, most of them are based on the same toxicity dataset and chemical speciation methodology as laid down in the 2008 European Union Environmental Risk Assessment Report (RAR). Since then, further insights into the toxic effects of nickel on aquatic species have been gained, and new data and methodologies have been generated and implemented using the predicted-no-effect-concentration (PNEC)-pro tool. The aim of the present study is to provide maximum transparency on data revisions and how this affects the derived environmental quality standards. A case study with 7 different ecoregions was used to determine differences in species sensitivity distributions and in hazardous concentrations for $5 \%$ of the species (HC5) values between the original Ni-RAR BLMs and the PNEC-pro BLMs. The BLM parameters used were pH dependent, which extended the applicability domain of PNEC-pro up to a $\mathrm{pH}$ of 8.7 for surface waters. After inclusion of additional species and adjustment for cross-species extrapolation, the HC5s were well within the prediction range of the RAR. Based on the latest data and scientific insights, transfer functions in the user-friendly PNEC-pro tool have been updated accordingly without compromising the original considerations of the Ni-RAR. Environ Toxicol Chem 2017;9999:1-10. (C) 2017 SETAC
\end{abstract}

Keywords: Bioavailability Biotic ligand model Metals Nickel HC5 values Risk assessment Surface water monitoring

\section{INTRODUCTION}

The importance of explicitly considering bioavailability in the development of water and sediment quality criteria for metals has been recognized for quite some time, and environmental quality standards (EQS) that incorporate this concept are now being considered for implementation by regulatory authorities. Although the first-tier risk assessment consists of the comparison of total dissolved water concentrations with a generic dissolved EQS, it is recognized that compliance with generic EQS does not adequately predict the actual level of ecological protection. Both overestimations and underestimations of actual risks as a result of not accounting for site-specific bioavailability have been reported [1]. To overcome this shortcoming, bioavailability corrections for metals, normalizing for variations in site-specific water chemistry, were introduced as a second-tier risk assessment.

Biotic ligand models (BLMs) have been developed for several metals to address bioavailability. The BLM is an adaptation of the gill surface interaction model $[2,3]$ modified by many other researchers [4-8] and the free ion activity model of toxicity $[9,10]$. The hypothesis of the BLM is not simply that toxicity is related to total dissolved metal concentrations, but that both metal-ligand complexation and metal interaction with

This article includes online-only Supplemental Data.

* Address correspondence to anja.verschoor@rivm.nl

Published online 22 February 2017 in Wiley Online Library

(wileyonlinelibrary.com).

DOI: $10.1002 /$ etc. 3772 competing cations at the site of action of toxicity need to be considered. To date, BLMs are acknowledged as useful concepts to determine site-specific risks [11]. Because full BLMs are based on both toxicological and chemical databases and require multiple complex calculations, several simplifications and user-friendly tools have been introduced in recent years. As a consequence, the full BLMs are only used case by case by BLM developers and a small group of scientists. In 2013, the Predicted-No-Effect-Concentration (PNEC)-pro 5 software was launched [12], which incorporates BLMs for second-tier EQS compliance following the Water Framework Directive [13]. Other simplified tools have been derived from full BLMs to facilitate the work of water managers and regulators. A recent review by Rüdel et al. [14] provides an overview of bioavailability tools and experiences in field cases of surface waters over Europe [14]. Figure 1 shows a comparison of the calculation steps of the full BLM and those of some simplified approaches. Whereas the full BLMs require the input of many water chemistry parameters and a combination of advanced speciation modeling, biotic ligand modeling, and statistical modeling, the simplified tools calculate the hazardous concentration for 5\% of the species (HC5) in a single step, using only a reduced set of significant input parameters.

The European Union Risk Assessment Reports (RARs) incorporated chronic BLMs for various metals, including zinc [15], nickel [16], and copper [17]. Typically, these RARs present in-depth research reviews of the metal of interest, including chronic toxicity data for a large range of organisms. Risk assessments were performed and documented using the data, models, and technical guidelines 

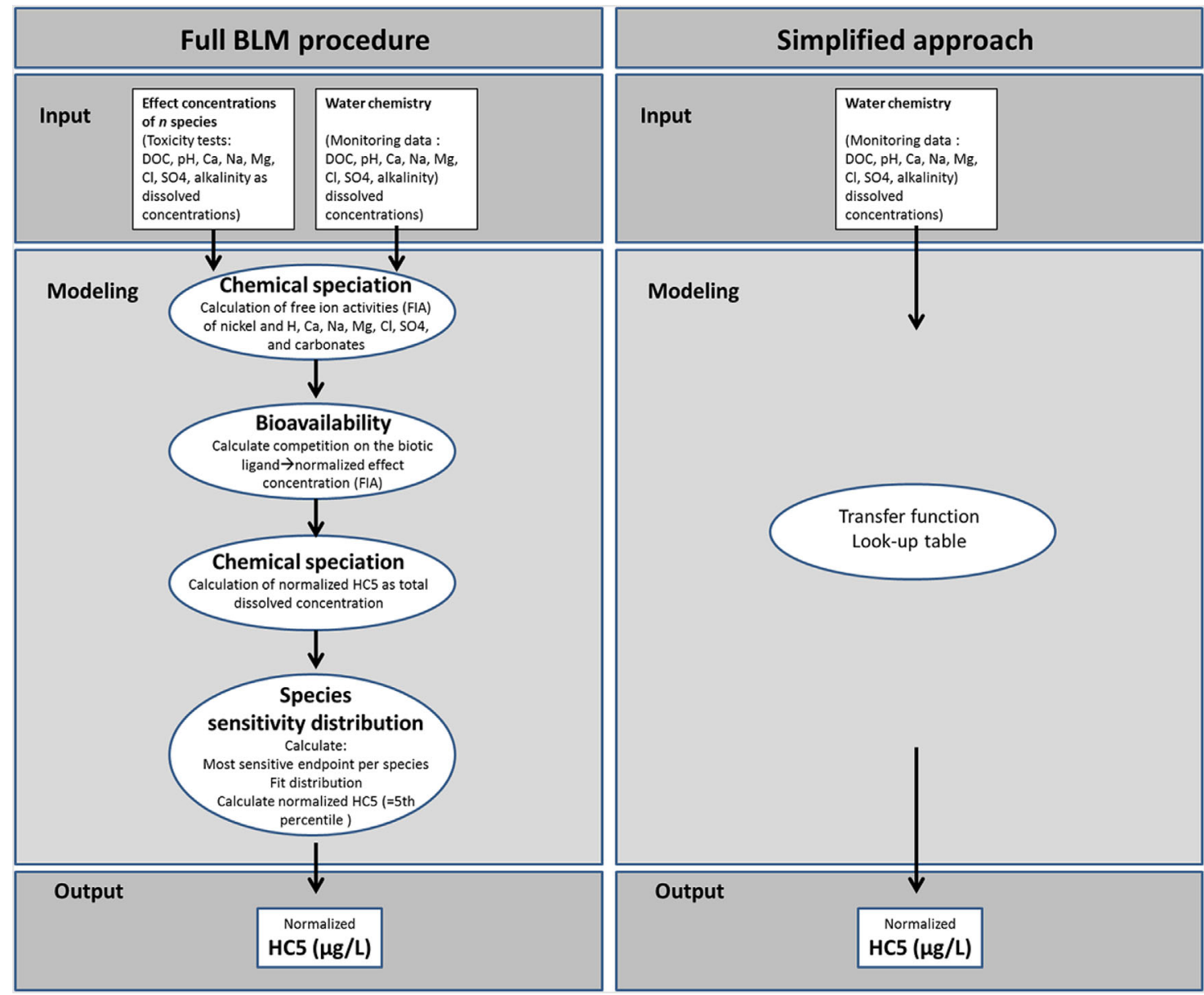

Figure 1. Overview of full biotic ligand model (BLM) calculations and simplified approaches to account for bioavailability in the site-specific hazardous concentration for $5 \%$ of the species (HC5). DOC $=$ dissolved organic carbon.

available at that time. Over the years, more data on toxicity have been generated, and new insights and methodologies have become available. Support of full-BLM modeling is therefore necessary to be able to keep the simplified models up to date.

In 2011, the European Commission published a guidance document [18] promoting the derivation of BLM-based EQS for metals and metal compounds in the context of the Water Framework Directive [19]. Shortly afterward, a revision of the Water Framework Directive and EQS directives [20] stated that the EQS for nickel can be based on bioavailable concentrations. Thus the risk assessment of nickel, in terms of scientific foundation and soundness, required immediate special attention. The EQS is an authorized value that protects the ecosystem from effects of long-term exposure. When many species are tested, as is the case for nickel, the EQS may be based on species sensitivity distributions (SSDs), from which the HC5 is estimated. Remaining uncertainty around the HC5 should be accounted for by an assessment factor.

In 2011, we implemented full BLMs for copper, nickel, and zinc in the modeling software program $\mathrm{R}$ for scientific research purposes [1]. A simplified tool for regulatory purposes, called PNEC-pro, was subsequently derived from the full BLM normalization procedure to facilitate routine evaluation of bioavailability for these metals in freshwater systems. This was achieved by stepwise regression of
full-BLM HC5 values of 371 water types, with corresponding water chemistry parameters, which resulted in transfer functions with 1,2 , or 3 parameters [21]. These transfer functions were included in PNEC-pro, which selects the most accurate function for a given set of water chemistry monitoring data [12]. For nickel, original chronic toxicity data and bioavailability models from the Ni-RAR were used as a starting point, but changes reported in literature since 2008 were carefully reviewed and, if valid, adopted by the Ni-BLM in PNEC-pro (Ver 5). These changes included: revised chronic toxicity data and tested species; revised settings for the chemical speciation calculations; and critical selection of water quality data, using only measured (not estimated) environmental variables (dissolved organic carbon [DOC], $\mathrm{Ca}, \mathrm{Mg}, \mathrm{Na}$ ).

The present study aimed to quantify the net consequences for the HC5 of these scientific progressions over time. Thus, the present study clarifies the adaptations to the full-BLM normalization procedure regarding chronic toxicity data as well as read-across and speciation calculations; quantifies the impact of these adaptations for the calculated full BLM HC5 of nickel; optimizes agreement between full BLMs underlying PNEC-pro and Ni-RAR; and presents simplified transfer functions for nickel that mimic the Ni-RAR (2008) methodology. The results were then implemented in a new updated (Ver 6) of PNEC-pro, and made accessible online, free to all users [12]. 


\section{MATERIALS AND METHODS}

\section{Full BLMs and simplified tools}

Table 1 shows an overview of the models and tools used in the present study. For clarity, we distinguish RAR-BLMs and RAR-tool, and PNEC-pro BLMs and PNEC-pro tool, to indicate the full BLMs and the simplified tool respectively. The PNECpro BLMs represent an operational multi-BLM calculation procedure, involving speciation calculation and original BLM algorithms. Version 5 of PNEC-pro was released in 2013; earlier versions were not publicly available. The refinements resulting from the present study are implemented in PNEC-pro 6 (available free of charge online [12]).

The reference method is laid down in the Ni-RAR [16]. The full BLM of the Ni-RAR is not available as a tool; HC5 values calculated with the full BLMs [22] are presented in Appendix G of the Ni-RAR as look-up tables for Ceriodaphnia dubia, Daphnia magna, Oncorhynchus mykiss, and Pseudokirchneriella subcapitata. This is done for $3 \mathrm{pH}$ values (7, 7.5, and 8.1), 13 DOC values between 1 and $25 \mathrm{mg} / \mathrm{L}$, and 17 hardness values between 6 and $320 \mathrm{mg} \mathrm{CaCO}_{3} / \mathrm{L}$. If a given DOC, $\mathrm{pH}$, and hardness is not present in the look-up table, the HC5 needs to be estimated by interpolation. The look-up tables for other species are not documented, so Ni-RAR HC5 values cannot be reproduced.

Transfer functions form an alternative to look-up tables and are able to compute HC5 without interpolation. The general approach and sequence of the modeling steps in the present study are as follows: update of Ni-RAR toxicity database; update of Ni-RAR bioavailability models; check of full BLM against Ni-RAR HC5 for ecoregions; and derivation of transfer functions based on full-BLM calculation for 371 water types using regression models.

Generally, the accuracy of the estimated HC5 increases with the number of parameters in the transfer function [21]. Therefore, PNEC-pro contains 5 transfer functions, with data on DOC as a minimum input variable required. When additional parameters are present, such as $\mathrm{pH}, \mathrm{Ca}, \mathrm{Na}$, or $\mathrm{Mg}$, PNEC-pro will apply the most accurate transfer function, with a maximum of 3 parameters [12]. The chemical composition of these water types is provided in the Supplemental Data. The validity of the BLMs and transfer functions is related to the range of the physicochemical conditions under which the test species were cultured. When water types are outside the boundaries of this

Table 1. Models and tools

\begin{tabular}{|c|c|c|c|}
\hline & Full BLI & $\longrightarrow$ & Simplified tool \\
\hline \multirow[t]{3}{*}{ RAR } & 216 toxicity data & & Look-up tables \\
\hline & 31 species & $\longrightarrow$ & Input parameters: \\
\hline & 4 BLMs & & DOC, pH, Ca (obligatory) \\
\hline \multirow[t]{4}{*}{ PNEC-pro 5} & 124 toxicity data & & Transfer functions \\
\hline & 23 species & $\longrightarrow$ & Input parameters: \\
\hline & 3 BLMs & & DOC (obligatory) \\
\hline & & & $\mathrm{pH}, \mathrm{Ca}, \mathrm{Na}, \mathrm{Mg}$ (optional) \\
\hline \multirow[t]{4}{*}{ PNEC-pro 6} & 233 toxicity data & & Updated transfer functions \\
\hline & 28 species & $\longrightarrow$ & Input parameters: \\
\hline & 4 BLMs & & DOC (obligatory) \\
\hline & & & $\mathrm{pH}, \mathrm{Ca}, \mathrm{Na}, \mathrm{Mg}$ (optional) \\
\hline
\end{tabular}

$\mathrm{BLM}=$ biotic ligand model; RAR $=$ Risk Assessment Report; PNEC = predicted no-effect concentration; $\mathrm{DOC}=$ dissolved organic carbon. applicability domain (specified in Section 2 of the Supplemental Data), calculations should be considered carefully. Recently, Nys et al. [23] showed that the toxicity of $\mathrm{Ni}$ at higher $\mathrm{pH}$ is underestimated by the Ni-RAR BLM, and proposed a new set of BLM parameters for use at $\mathrm{pH}>8.7$. These refined BLM parameters have been adopted in PNEC-pro 6.

\section{Toxicity data}

Chronic toxicity data for freshwater organisms and the associated BLMs that were used in the Ni-RAR were evaluated in detail. All no-observed-effect concentration (NOEC) or $10 \%$ effect concentration (EC10) data for all tested aquatic species included in the Ni-RAR and PNEC-pro 5 were individually reevaluated. Table 2 provides an overview of the toxicity data provided in the Ni-RAR and in the PNEC-pro 5 and 6 full BLMs. The complete evaluation is provided in the Supplemental Data, Section 1. Details of the selected NOEC or EC10 values, including the corresponding water chemistry, are provided in the Supplemental Data. The Ni-RAR contains 216 toxicity data of 31 species. The PNEC-pro5 database contained a subset of the Ni-RAR of 124 toxicity data of 23 species [24]. The selection covers the following criteria: only records with complete sets of $\mathrm{DOC}, \mathrm{pH}, \mathrm{Ca}, \mathrm{Mg}$, and $\mathrm{Na}$ concentrations were adopted in the database; only NOEC values and no EC10 values were added; and only records that were not used for the derivation of the BLMs, to avoid cross-reference.

Furthermore, data for 3 species were excluded from the PNEC-pro 5 datasets: the rotifer Brachionus calyciflorus, the insect Chironomus tentans, and the snail Lymnaea stagnalis. This exclusion was motivated by the fact that the data were not publicly available at the time PNEC-pro 5 was developed, and the Ni-RAR did not provide the required input for a full-BLM calculation. Within PNEC-pro 6, these data were incorporated, based on the publication of the Schlekat et al. study [25].

For the development of PNEC-pro 6, a new set of toxicity and speciation data was constructed to mimic the Ni-RAR toxicity database as closely as possible and was used with a new set of full BLMs, further referred to as PNEC-pro 6. Records that were originally used for BLM development were also included. If both NOEC and EC10 values were available for the same test, the EC10 value was used. At present, the NOEC is considered only a more appropriate measure than the EC10, if the confidence limits around the EC10 are very wide. However, no attempt was undertaken to fill in data gaps of essential BLM input parameters, such as DOC, $\mathrm{Ca}, \mathrm{Mg}, \mathrm{Na}$, and $\mathrm{pH}$. Therefore, incomplete records were still not included in the toxicity database.

\section{BLMs and cross-species extrapolation}

Biotic ligand models are used to normalize toxicity data to target waters. They are species-specific models and are based on chronic toxicity data established for algae, crustaceans, and fish. However, chronic BLMs are not available for all species of the aquatic ecosystem. Several nickel BLMs for chronic toxicity of Ni were published for the alga $P$. subcapitata, the crustaceans D. magna and C. dubia, and the fish O. mykiss (Table 3). Crossspecies extrapolation was employed to correct the NOEC or EC10 of test species for which a BLM is lacking. These extrapolations were checked for validity for a snail, a rotifer, an insect, and an aquatic plant [25]. The intention of the present study was to adopt the concept and assumptions of the Ni-RAR, but it seemed inappropriate to neglect the improvements and corrections that were published shortly after finalization of the Ni-RAR. For example, the Ni-RAR for algae used a BLM that 
Table 2. Overview of species, their effect concentrations in $\mu \mathrm{g} / \mathrm{L}$ (NOEC or EC10), and number of records $(n)$ in the Ni-RAR and in the PNEC-pro databases ${ }^{\mathrm{a}}$

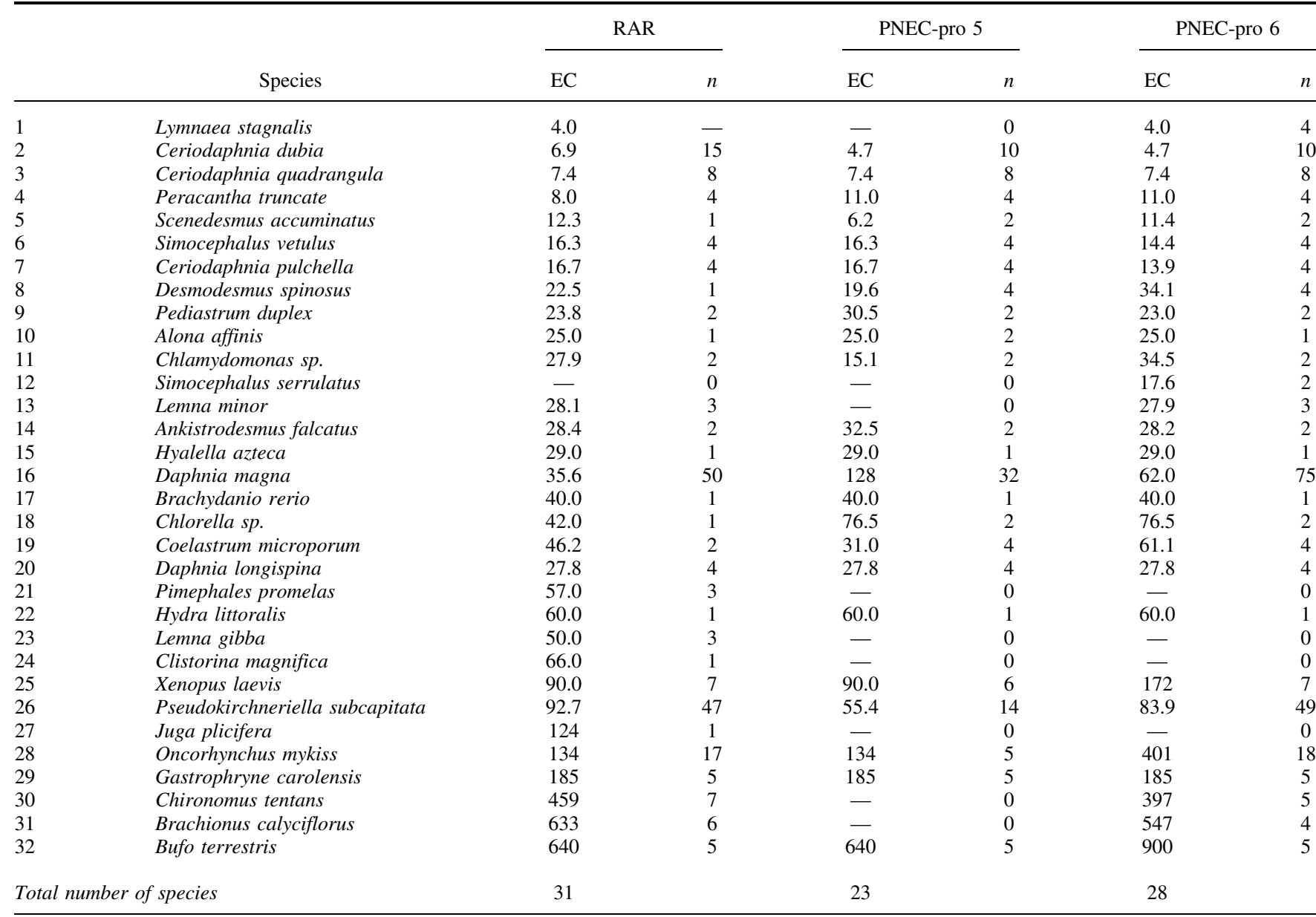

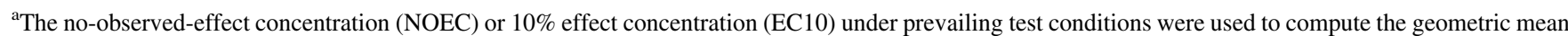
of the most sensitive endpoint for individual species. Species are ranked by decreasing sensitivity, following the nickel Risk Assessment Report (RAR).

was not suited to predict nickel toxicity over a wide $\mathrm{pH}$ range [26]. The toxicity of $\mathrm{Ni}^{2+}$ to algae was observed to increase with increasing $\mathrm{pH}$. Although the BLMs in the Ni-RAR were stateof-the-art at the time the Ni-RAR was written, they were still in an early stage of development. Compared with the Ni-RAR, PNEC-pro 5 and 6 use more recent BLM algorithms. These BLMs were published in peer-reviewed journals [26-28] after the Ni-RAR was finalized, except for the C. dubia BLM.

For higher aquatic plants that are primary producers, the BLM for the primary producer algae $P$. subcapitata is expected to be ecologically most relevant. It is noteworthy that although the invertebrate $D$. magna is a consumer, the regression fit was best $(p<0.05)$ for the algae. Therefore, within the Ni-RAR the D. magna BLM was used to assess Ni toxicity to higher aquatic plants. Application of this algal BLM resulted mostly in more stringent normalized NOEC or EC10 values (see Appendix G5 of the Ni-RAR). For this reason, PNEC-pro 6 uses the algal BLM for higher plants, as did PNEC-pro 5.

For rotifers, the D. magna BLM was used by the Ni-RAR, by PNEC-pro 5, and also by PNEC-pro 6. The Ni-RAR, however, used an earlier version of the D. magna BLM [22]. The parameters corresponding with the selected BLMs are shown in Table 3.

For mollusks and hydra, the $C$. dubia BLM from the Ni-RAR was also selected in the present study. The $C$. dubia BLM was not included in PNEC-pro 5 because, unlike all the other BLMs in the Ni-RAR, it was never published in peer-reviewed literature. The Ni-RAR used the $C$. dubia BLM for mollusks and the freshwater polyp Hydra sp. because it was empirically the best fitting model. It remains unclear in the Ni-RAR whether the differences in goodness-of-fits between $C$. dubia and D. magna are significant. The D. magna BLM resulted in stricter normalized NOEC or EC10 values for 7 ecoregions than the C. dubia BLM. For example, for water types with high dissolved organic matter, such as the Dutch ditches, the Ni-RAR showed that the $C$. dubia model predicted NOECs that were more than 5 times higher than predicted with the D. magna model.

In PNEC-pro 6, D. magna and C. dubia NOECs were normalized with their respective BLMs. For other cladocerans, insects, and amphipods, the Ni-RAR selects the more stringent of the D. magna and C. dubia BLMs. This means that, for each test species in this group, 2 normalizations were executed and the lowest NOEC of the 2 approaches was selected. This approach follows that of the Ni-RAR. It concerns 11 species, with a total number of 120 of 233 toxicity test data. The D. magna BLM was used for all cladocera, including C. dubia, in PNEC-pro 5. An overview of the assignment of the BLMs to different species is described in the Supplemental Data.

\section{Chemical speciation}

The chemical speciation of nickel (specifically $\mathrm{Ni}^{2+}$ ) was computed with Windermere Humic Aqueous Model (WHAM) 6 [29], which is the same software version that was used for the 
Table 3. Overview of BLM model parameters used in the Ni-RAR and PNEC-pro models ${ }^{\mathrm{a}}$

\begin{tabular}{|c|c|c|c|c|c|c|c|c|c|}
\hline & & $\begin{array}{c}\log \\
\text { KHBL }\end{array}$ & $\begin{array}{c}\log \\
\mathrm{KCaBL}\end{array}$ & $\begin{array}{c}\log \\
\mathrm{KMgBL}\end{array}$ & $\mathrm{S}_{\mathrm{pH}}$ & Ref. & RAR & $\begin{array}{c}\text { PNEC-pro } \\
5\end{array}$ & $\begin{array}{c}\text { PNEC-pro } \\
6\end{array}$ \\
\hline \multicolumn{10}{|c|}{ Algae and higher plants } \\
\hline Hybrid: $\mathrm{pH}<8.2$ & P. subcapitata & & & 3.3 & 0.143 & [26] & & $\mathrm{x}$ & $\mathrm{x}$ \\
\hline Hybrid: $\mathrm{pH}>8.2$ & Mean of Lemna minor and $P$. subcapitata & & & 3.3 & 0.906 & [23] & & & $\mathrm{x}$ \\
\hline \multicolumn{10}{|l|}{ Invertebrates } \\
\hline Hybrid: $\mathrm{pH}<8.2$ & C. dubia & & 3.53 & 3.57 & 0.859 & [22] & $\mathrm{x}$ & & $\mathrm{x}$ \\
\hline \multicolumn{10}{|c|}{ - } \\
\hline Hybrid & Oncorhynkus mykiss & & 3.6 & 3.6 & 0.324 & [28] & $\mathrm{x}$ & $\mathrm{x}$ & $\mathrm{x}$ \\
\hline
\end{tabular}

${ }^{a} \log K$ is the biotic ligand (BL) affinity constant, and $S_{\mathrm{pH}}$ is a regression factor to account for the $\mathrm{pH}$ effect in hybrid BLMs. An x indicates which BLMs were selected by the RAR and by PNEC-pro.

$\mathrm{BLM}=$ biotic ligand model; RAR $=$ Risk Assessment Report; PNEC $=$ predicted no-effect concentration.

BLMs in the Ni-RAR. Speciation of nickel is determined by the constants for chemical equilibrium. Adjustments to the standard settings of WHAM 6 that were described in the Ni-RAR were also adopted by PNEC-pro 5 and 6 . This concerns accordance of the stability constants in WHAM with the National Institute of Standards and Technology (NIST) reference database [30] and a binding constant of $\mathrm{Ni}$ to fulvic acids of 1.75 instead of 1.4 $[28,31]$. An overview of the parameterization of chemical speciation calculations is provided in the Supplemental Data, Section 2. Speciation parameters that were used in WHAM calculations differed in some points between PNEC-pro 5 and 6 and the Ni-RAR. These differences were as follows: active fulvic acids in the water types (50\% vs $40 \%)$; the stability constant of $\mathrm{NiCl}(-0.43 \mathrm{vs}+0.41)$ [30]; and the assumption for a background DOC concentration in reconstituted toxicity test waters; Ni-RAR assumes a value of 0 , and PNEC-pro 5 assumes a minimum of $0.3 \mathrm{mg} \mathrm{C} / \mathrm{L}$. The settings for DOC in PNEC-pro 6 were according to the Ni-RAR.

\section{Performance testing}

In the Ni-RAR, 7 ecoregion scenarios were identified to represent frequently occurring freshwater types with characteristics covering a wide range of physicochemical conditions occurring in the European Union (e.g., oligotrophic, acidic, alluvial aquatic systems). These scenarios were selected based on the expectation that they would provide ranges of $\mathrm{Ni}$ bioavailability, while remaining within the 10th and 90th percentile ranges of $\mathrm{pH}$, hardness, and DOC [16]. The chronic toxicity data for nickel were normalized toward the physicochemical conditions prevailing in the different typical ecoregion scenarios (Table 4). Full-BLM modeling for development of the PNEC-pro 5 and 6 tool was performed to normalize the toxicity data. The geometric mean NOEC of the most sensitive endpoint for each species was used to construct an SSD. The HC5 values were computed from the fitted log-normal distribution as was done in the Ni-RAR and compared with the reported Ni-RAR outcomes for the ecoregion scenarios. The 5th percentile of the distribution is represented as the HC5 value. The lower 50\% confidence interval associated with the HC5 concentration is represented as the HC5-50. The HC5 values in the present study represent HC5-50 values.

\section{Construction of transfer functions}

The nonlinear equations in the full BLMs contain 8 measured variables (pH, DOC, $\mathrm{Ca}, \mathrm{Na}, \mathrm{Mg}, \mathrm{Cl}, \mathrm{SO}_{4}, \mathrm{HCO}_{3}$ ) of 372 water types in The Netherlands, which are transformed into linear equations via (backward and forward) multiple regression analyses to select the dominant variables [21]. These multiple regression models have the general notation:

$$
\mathrm{HC} 5=a+(b \times \operatorname{var} 1)+(\mathrm{c} \times \operatorname{var} 2)+(d \times \operatorname{var} 3) \ldots
$$

To test whether the model is significantly improved by addition of a variable, the Akaike Information Criterion (AIC) was used [32].

\section{BLM data gaps}

To run full BLMs, it is essential to obtain the required input parameters that are included in that specific model, such as DOC, $\mathrm{pH}, \mathrm{Ca}, \mathrm{Mg}, \mathrm{Na}, \mathrm{Cl}, \mathrm{CO}_{3}$ and $\mathrm{SO}_{4}$. However, the Ni-RAR provides ecotoxicity records in which (some of) these crucial data are missing. Estimation functions for $\mathrm{Mg}$ and $\mathrm{Na}$ from $\mathrm{Ca}$ concentrations were suggested by Peters et al. [33] to fill these data gaps. We tested the validity of these functions for surface waters in The Netherlands, using a national monitoring database (iBever 3.7.200), supplemented with regional data. This yielded 1200 useful records, covering 9 water types in The Netherlands over the period 2007 to 2010 and covering a wide range of $\mathrm{Ca}$ concentrations (1.7-220 mg Ca/L).

\section{RESULTS AND DISCUSSION}

\section{Model comparisons}

In recent years, new nickel toxicity and speciation data and BLM models have become available via peer-reviewed literature (e.g., speciation constants) or via modifications of earlier (unpublished) studies (e.g., toxicity data). To quantify the effects of these modifications, the original BLMs with the initial configurations reported in the Ni-RAR were refined to reflect the latest scientific insights. The impact of these refinements on the calculated normalized HC5 is shown for 7 ecoregion water types in Figure 2 (see HC5 values in the Supplemental Data, Section 3). The HC5 values of PNEC-pro 6 BLMs are well within the uncertainty range reported in the $\mathrm{Ni}$ RAR, with a correlation coefficient of $0.999(n=7)$. The mean HC5 ratio between PNEC-pro BLMs and the Ni-RAR was 0.90.

The correlation of ecoregion HC5 values between PNEC-pro 5 BLMs and the Ni-RAR is low $(r=0.41)$. The use of different BLMs and different toxicity databases contributed to the observed differences. The fact that the most sensitive species 
(L. stagnalis) was not included in PNEC-pro 5 did not result in systematically lower HC5 values compared with the Ni-RAR for the ecoregions ( $p=0.65,2$-sided $t$ test). After normalization of the NOECs, L. stagnalis remains the most sensitive species, and thus it will have a major impact on the ultimate HC5. In PNEC-pro 6 this most sensitive species is included, with a better resemblance to Ni-RAR HC5 values as a result.

Although the moderately sensitive species also determine the shape of the SSD curve, their influence on the estimated HC5 is relatively small. The exclusion of the species Juga plicifera, Clistorina magnifica, Lemna gibba, and Pimephales promelas in PNEC-pro 5 and 6 was therefore negligible in its impact on HC5 values.

The BLM concept presumes that BLMs are species specific. This implies that species respond in a different way to changes in the physicochemical environment. This is reflected by the variations in the regression factor $\mathrm{S}_{\mathrm{pH}}$ between species, which describes the effect of $\mathrm{pH}$ on nickel. This means that certain species show a larger response to $\mathrm{pH}$ changes than others and, as a result their position relative to each other, may change. The ranking of species (as shown in Figure 3), and hence the position of species in the SSD, has an impact on the ecosystem's structure and likely can have an impact on functioning when a certain fraction of the species is affected by pollution. A different ranking of species in the SSDs among Ni-RAR, PNEC-pro 5, and PNEC-pro 6 is observed and is the result of different assignments of BLMs to individual species (crossspecies extrapolation). The largest difference in species ranking was found between the Ni-RAR and PNEC-pro 5, with a rank correlation of approximately 0.71 . The agreement in species ranking is better between the Ni-RAR and PNEC-pro 6 $(r \approx 0.94)$. The differences in species ranking did not occur for the most sensitive species; for all ecoregions, L. stagnalis remains the most sensitive species, also after normalization of the NOEC, followed by C. dubia. Lemna gibba, the second most sensitive species in the Ni-RAR in, for example, the acidic Swedish lake, is not included in the PNEC-pro 6 dataset, because a complete set of physicochemical test conditions was not published.

For cladocera, amphipods, and insects except $C$. dubia and D. magna, PNEC-pro 6 applied 2 BLMs and selected the most stringent normalized NOEC. It appeared that not one of these BLMs was consistently the most stringent (Supplemental Data, Section 4). In the acidic lake and the Dutch Ditch, the D. magna BLM led to the lowest HC5 values, whereas in the other water types the lowest HC5 values were computed by the $C$. dubia BLM. The ratio between EC10 values normalized with D. magna and C.dubia BLMs varied from 0.11 to 4.7. Because PNEC-pro 5 only used the D. magna BLM for all invertebrates, relatively high $\mathrm{HC} 5$ values were seen in a number of cases.

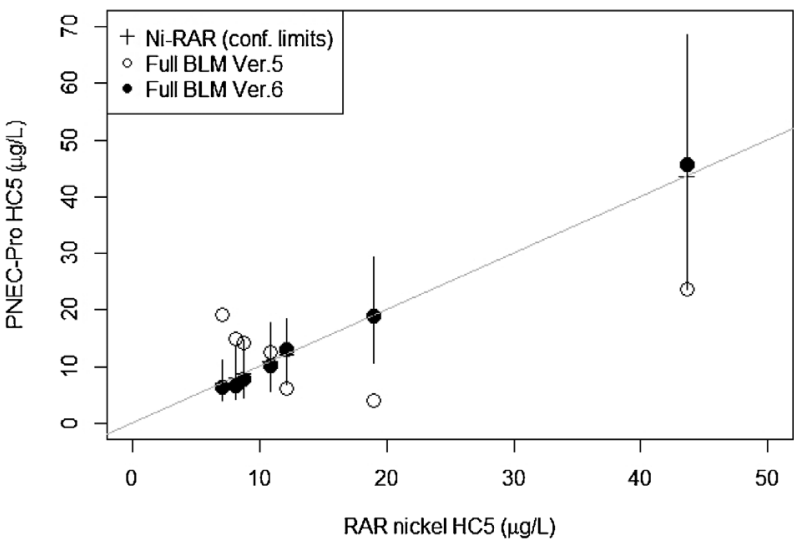

Figure 2. Comparison of the nickel HC5 computed by PNEC-pro Ver 5 and 6 and with the nickel BLM of the Ni-RAR for 7 ecoregions (from left to right: Monate, Otter, Ebro, Rhine, Acidic lake, Teme, Dutch ditch). $\mathrm{HC} 5=$ hazardous concentration for $5 \%$ of the species; PNEC $=$ predicted no-effect concentration; BLM $=$ biotic ligand model; $\mathrm{RAR}=$ European Union Risk Assessment Report.

\section{Transfer functions}

Table 5 shows the transfer functions of PNEC-pro 6, which were derived from full-BLM calculations. Transfer functions of PNEC-pro 5 were published previously [21]. The fits of the transfer functions with the full-BLM HC5 are shown in Figure 4. With DOC as the sole input parameter of the water sample, HC5 was estimated with a residual standard error of $7.3 \mu \mathrm{g} / \mathrm{L}$ using a one-parameter model. The uncertainty of the estimated HC5 can be reduced by providing additional monitoring parameters. The $\mathrm{pH}$ will contribute most to the improvement of the estimated HC5, as can be seen by the lowest AIC and the higher adjusted $r^{2}$. Depending on the availability of input parameters, PNEC-pro 6 automatically selects the most reliable function. Three parameter models-requiring DOC, $\mathrm{pH}$, and $\mathrm{Ca}, \mathrm{Na}$, or $\mathrm{Mg}$ - perform very well, and all have an adjusted $r^{2}$ of approximately 0.9 . These models have similar statistical significance as functions that include all BLM parameters. For particular combinations of water chemistry parameters, negative HC5 values were predicted by the transfer functions. In that case, an out-off domain warning is generated.

\section{Water chemistry data gaps}

To cope with missing water chemistry parameters, the Ni-RAR provides data matrices presented as look-up tables (see Appendix $G$ in the European Union RAR [16]). The NOEC values can be determined in this way via interpolation. The other 7 input parameters required for full-BLM

Table 4. Ecoregion scenarios and their major input parameters used for SSD calculations ${ }^{\mathrm{a}}$

\begin{tabular}{|c|c|c|c|c|}
\hline Ecoregion & Type & $\mathrm{pH}$ & $\mathrm{DOC}(\mathrm{mg} / \mathrm{L})$ & Hardness $\left(\mathrm{mg} \mathrm{CaCO}_{3} / \mathrm{L}\right)$ \\
\hline River Teme (UK) & Medium (rivers with flow rate of $\pm 200000 \mathrm{~m}^{3} / \mathrm{d}$ ) & 7.6 & 8.0 & 159 \\
\hline River Otter (UK) & Medium (rivers with flow rate of $\pm 200000 \mathrm{~m}^{3} / \mathrm{d}$ ) & 8.1 & 3.2 & 165 \\
\hline River Rhine (NL) & Large (rivers with flow rate of $\pm 1000000 \mathrm{~m}^{3} / \mathrm{d}$ ) & 7.8 & 2.8 & 217 \\
\hline River Ebro (ES) & Mediterranean river & 8.2 & 3.7 & 273 \\
\hline Ditch (NL) & Small (ditches with flow rate of $\pm 1000 \mathrm{~m}^{3} / \mathrm{d}$ ) & 6.9 & 12 & 260 \\
\hline Neutral acidic lake $(\mathrm{S})$ & Acidic system & 6.7 & 3.8 & 27.8 \\
\hline Lake Monate (I) & Oligotrophic systems & 7.7 & 2.5 & 48.3 \\
\hline
\end{tabular}

${ }^{\mathrm{a}} \mathrm{pCO}_{2}=3.510^{-4}$ atm; molar $\mathrm{Ca}: \mathrm{Mg}$ ratios $=3: 1$.

$\mathrm{SSD}=$ species sensitivity distribution; $\mathrm{DOC}=$ dissolved organic carbon. 
calculations are either kept at a default value or approximated with generic relations with other water characteristics [33]. The capability of the transfer functions to predict $\mathrm{Mg}$ and $\mathrm{Ca}$ concentrations is presented in Figure 5. It shows that the vast majority of measurements of $\mathrm{Mg}$ and $\mathrm{Na}$ are outside the acceptable reliability range of the estimation functions. A structural and significant underestimation $(99.2 \%$ for $\mathrm{Mg}$, and $88.9 \%$ for $\mathrm{Na}$ ) is observed, of which $>30 \%$ have a factor higher than 2. The estimation functions thus introduce significant additional uncertainty in the calculation of the HC5, which translates into a general overestimation of the site-specific EQS and consequently in underprotection of the ecological risks. Peters et al. [34] showed that estimation of DOC concentrations from dissolved iron concentrations using a simple empirical function increases uncertainty in $\mathrm{HC} 5$ prediction by up to $28 \%$, expressed as relative error [34]. To apply (full or simplified) BLM models, we propose to use measured data only, and refrain from estimations via regionally derived empirical functions.

\section{CONCLUSIONS}

Monovariable and multivariable linear transfer functions were derived to simulate the full-BLM calculations. These functions are used interactively-that is, depending on the availability of monitoring parameters-in PNEC-pro 6. The simulation of BLMs by regression functions enabled regulatory implementation of bioavailability corrections aiming at a refined risk assessment of surface waters. Bioavailability tools should be flexible enough that those can be improved using new data and insights; it is important to keep in mind that improvements should be made without compromising the initial considerations of the Ni-RAR. The present study shows
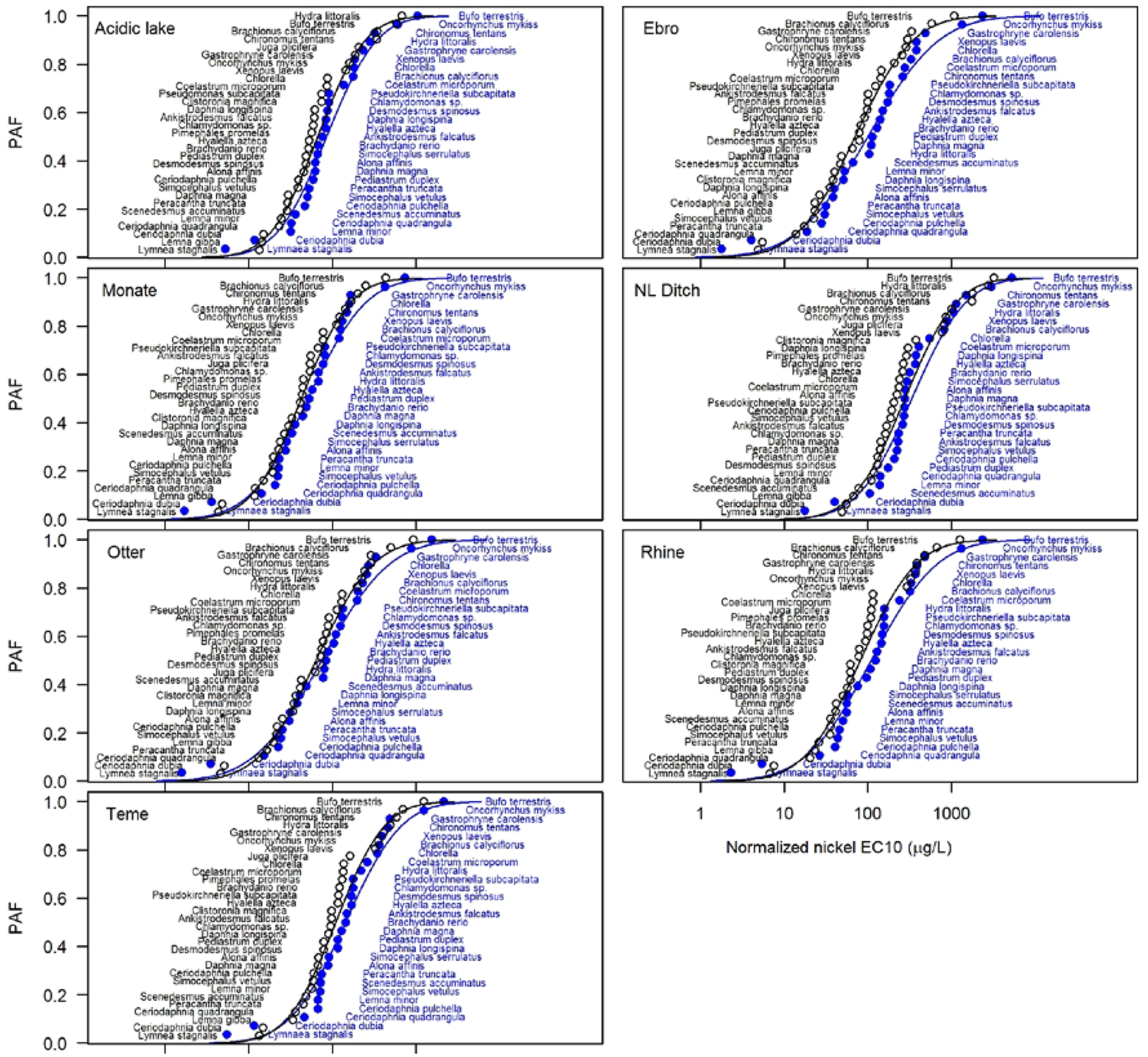

Normalized nickel EC10 ( $\mu \mathrm{g} / \mathrm{L})$

Figure 3. Species sensitivity distributions (SSDs) calculated with the Ni-RAR (black open markers) and PNEC-pro 6 (solid blue markers) for 7 selected ecoregions. The SSDs show the relation between normalized nickel no-effect concentrations and the potentially affected fraction of species (PAF). $\mathrm{PNEC}=$ predicted no-effect concentration; RAR $=$ European Union Risk Assessment Report; EC10 $=10 \%$ effect concentration; NL $=$ Netherlands. 
Table 5. Monoparameter and multiparameter models for estimation of HC5 for nickel in PNEC-pro $6^{\mathrm{a}}$

\begin{tabular}{|c|c|c|c|}
\hline Type/function & RSE & AIC & Adj. $r^{2}$ \\
\hline $6.15+1.50 \times \mathrm{DOC}$ & 8.3 & 2624 & 0.61 \\
\hline $4.72+1.50 \times \mathrm{DOC}+0.07 \times \mathrm{Mg}$ & 7.5 & 2553 & 0.68 \\
\hline \multicolumn{4}{|l|}{ Three-parameter models: } \\
\hline $107.70+1.42 \times \mathrm{DOC}-13.59 \times \mathrm{pH}+0.01 \times \mathrm{Na}$ & 4.2 & 2123 & 0.90 \\
\hline
\end{tabular}

${ }^{\mathrm{a}} \mathrm{HC} 5$ is expressed in $\mu \mathrm{g} / \mathrm{L}$, and DOC, $\mathrm{Mg}, \mathrm{Ca}$, and $\mathrm{Na}$ are expressed in $\mathrm{mg} / \mathrm{L}$.

HC5 $=$ hazardous concentration for 5\% of the species; RSE $=$ relative standard error; AIC $=$ Akaike Information Criterion; DOC $=$ dissolved organic carbon

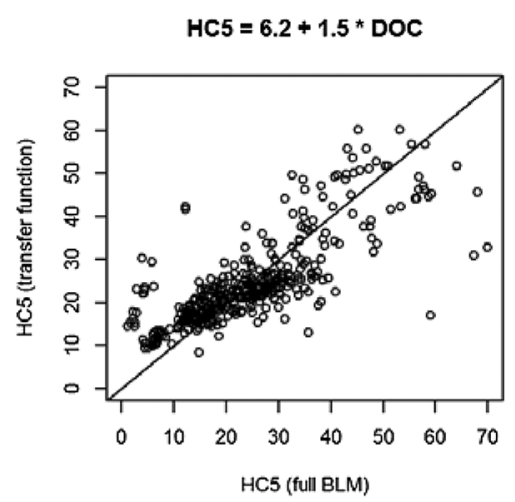

$\mathrm{HC} 5=107.7 \div 1.4{ }^{*} \mathrm{DOC}-13.6{ }^{\star} \mathrm{pH}+0.01^{\star} \mathrm{Na}$

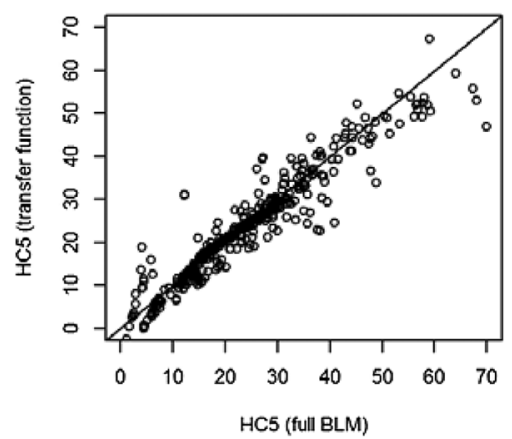

$94.4 \div 1.4 * \mathrm{DOC}-11.6 * \mathrm{pH}$

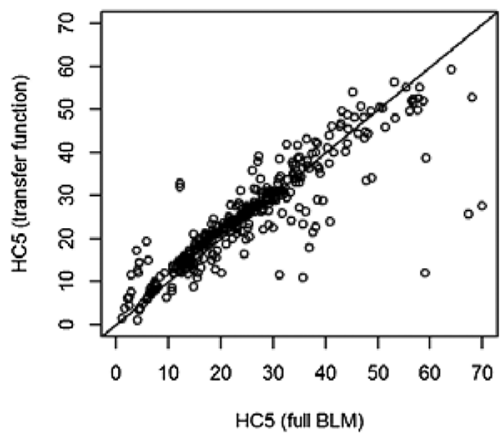

$\mathrm{HC} 5=122.1+1.4{ }^{\star} \mathrm{DOC}-16.4{ }^{\star} \mathrm{pH}+0.12^{\star} \mathrm{Ca}$

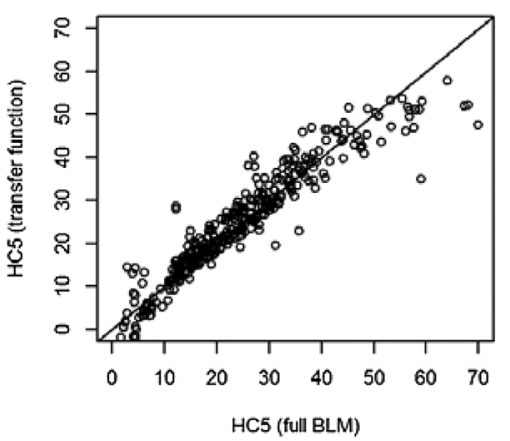

$\mathrm{HC} 5=4.7 * 1.5 * \mathrm{DOC}-0.07 * \mathrm{Mg}$

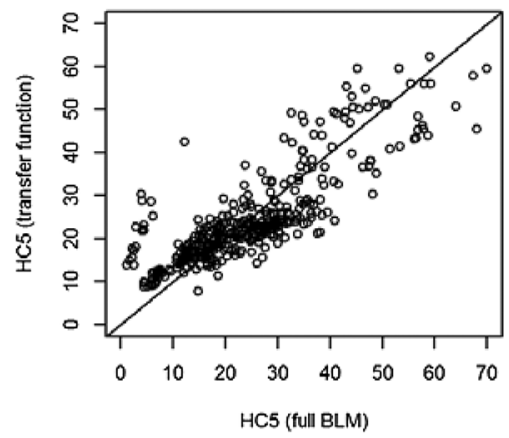

$\mathrm{HC} 5=109.5+1.4{ }^{\star} \mathrm{DOC}-13.9^{\star} \mathrm{pH}+0.09^{\star} \mathrm{Mg}$

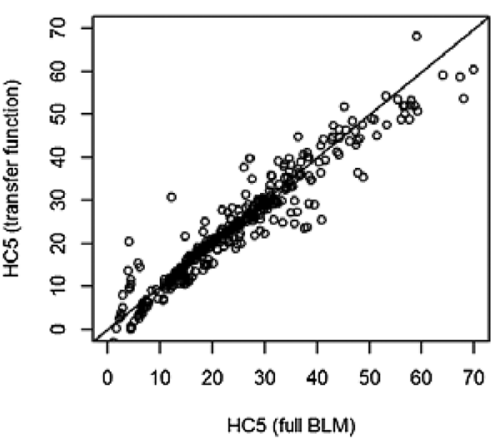

Figure 4. Goodness-of-fit of the transfer functions. Each dot represents a water type from the iBever database, which consists of a large variety of water types (rivers, lakes, brooks) in The Netherlands. The hazardous concentration for 5\% of the species (HC5) is expressed in $\mu \mathrm{g} / \mathrm{L}$, and the dissolved organic carbon (DOC), $\mathrm{Ca}, \mathrm{Na}$, and $\mathrm{Mg}$ are in $\mathrm{mg} / \mathrm{L}$. Line represents the perfect fit. $\mathrm{BLM}=$ biotic ligand model.
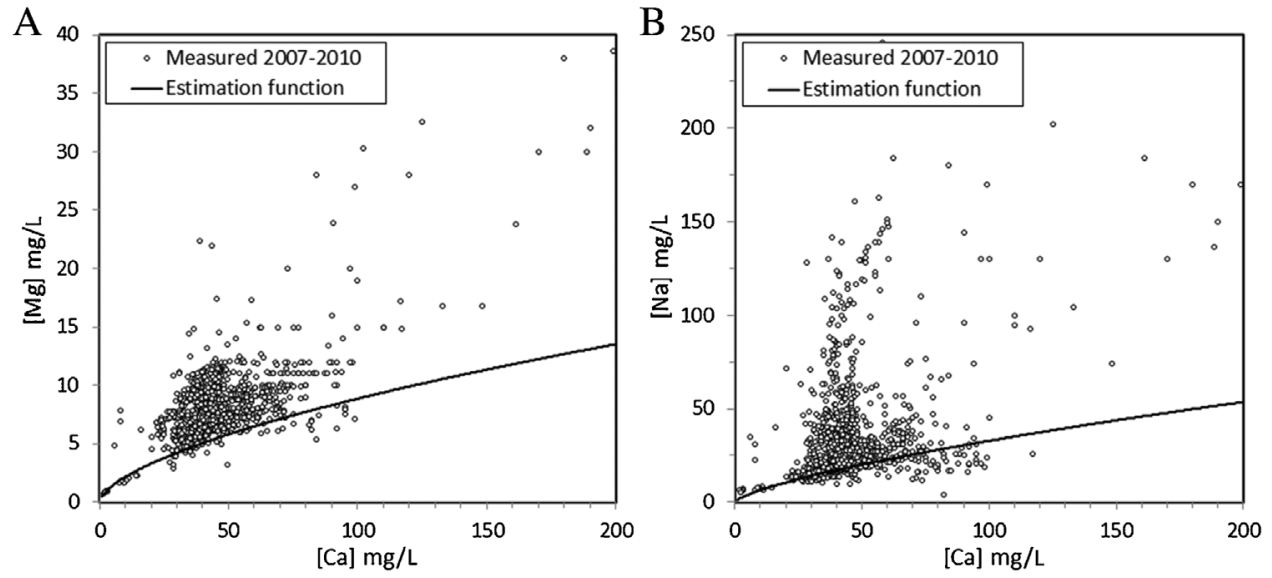

Figure 5. Relationship of $\mathrm{Ca}$ and $\mathrm{Mg}$ concentrations $(\mathbf{A})$ and $\mathrm{Ca}$ and $\mathrm{Na}$ concentrations $(\mathbf{B})$. Dots are measurements from year-round monitoring programs in The Netherlands, and solid lines represent the suggested estimation functions of Peters et al. [33]. 
the importance of operational, full-BLM modeling capability. This remains indispensable, because these mechanistic models allow us to incorporate new knowledge regarding species sensitivities, cross-species extrapolation issues, and DOC and chemical complexation.

For reliable legal implementation of BLMs, it is clear that choices remain to be made, for example, consideration of whether nonmeasured BLM parameters such as $\mathrm{Ca}, \mathrm{Mg}$, and DOC can be derived from simple relationships based on other environmental parameters without diminishing reliability and reproducibility through uncertainty propagation. Collinearity and relationships among environmental parameters are not universal and should be derived and applied for regional purposes at best.

The differences between the Ni-RAR methodology, published in 2008, and the modifications carried through in PNEC-pro were negligible and are discussed in detail. Overviews of differences in toxicity endpoints, biological species, and speciation constants are presented and disclosed. The overall result of the various adaptations and differences is demonstrated by normalized SSDs, which were produced with the Ni-RAR settings and with PNEC-pro 6 for 7 selected ecoregion scenarios. In addition, considerations of how to handle data gaps and other assumptions, such as default values for calculations, are discussed. These overviews add greatly to the transparency of the BLM methodology, which is inherently characterized by its complexity, and a subsequent confidence in the simplified, user-friendly tool.

Supplemental Data-The Supplemental Data are available on the Wiley Online Library at DOI: 10.1002/etc.3772.

Acknowledgment-The manuscript was written through contributions of all authors. All authors have given approval to the final version of the manuscript. The Dutch Ministry of Infrastructure and the Environment is gratefully acknowledged for its support. We thank the many users of PNEC. pro all over the world for their constructive suggestions and recommendations.

Data availability —Data, associated metadata, and calculation tools are available from the corresponding author (anja.verschoor@rivm.nl).

\section{REFERENCES}

1. Verschoor AJ, Vink JPM, de Snoo G, Vijver MG. 2011. Spatial and temporal variation of water type-specific no-effect concentrations and risks of $\mathrm{Cu}, \mathrm{Ni}$ and $\mathrm{Zn}$. Environ Sci Technol 45:6049-6056.

2. Pagenkopf GK. 1983. Gill surface interaction model for trace-metal toxicity to fishes: Role of complexation, $\mathrm{pH}$, and water hardness. Environ Sci Technol 17:342-347.

3. Pagenkopf GK, Russo RC, Thurston RV. 1974. Effect of complexation on toxicity of copper to fishes. J Fish Res Board Can 31:462-465.

4. Playle RC, Dixon DG. 1993. Copper and cadmium binding to fish gills: Estimates of metal-gill stability constants and modelling of metal accumulation. Can J Fish Aquat Sci 50:2678-2687.

5. Richards JG, Playle RC. 1998. Cobalt binding to gills of rainbow trout (Oncorhynchus mykiss): An equilibrium model. Comp Biochem Physiol C 119:185-197.

6. De Schamphelaere KAC, Janssen CR. 2002. A biotic ligand model predicting acute copper toxicity for Daphnia magna: The effects of calcium, magnesium, sodium, potassium, and pH. Environ Sci Technol $36: 48-54$

7. Hollis L, Burnison K, Playle RC. 1996. Does the age of metaldissolved organic carbon complexes influence binding of metals to fish gills? Aquat Toxicol 35:235-264.

8. Wood C, Playle RC, Hogstrand C. 1999. Physiology and modeling of mechanisms of silver uptake and toxicity in fish. Environ Toxicol Chem 18:71-83.
9. Morel F. 1983. Principles of Aquatic Chemistry. John Wiley \& Sons, Hoboken, NJ, USA.

10. Campbell DJ. 1995. Interactions between trace metals and aquatic organisms: A critique of the free ion activity model. In Tessier A, Turner D, eds, Metal Speciation and Bioavailability in Aquatic Systems. John Wiley \& Sons, Hoboken, NJ, USA, pp 45-102.

11. Scientific Committee on Health and Environmental Risks. 2009. Risk assessment report on copper and its compounds. Environmental Part, opinion adopted by written procedure on 12 February 2009. European Commission, Luxembourg.

12. Vink JPM, Verschoor AJ, Vijver MG. 2013. PNEC.pro: Software Release, Ver 5. Deltares Foundation, Utrecht, The Netherlands. [cited 2016 May 10]. Available from: www.PNEC-pro.com.

13. European Commission. 2000. Directive 2000/60/EC of the European Parliament and of the Council of 23 October 2000 establishing a framework for community action in the field of water policy. Official $J$ Eur Union L327:1-73.

14. Rüdel H, Díaz Muñiz C, Garelick H, Kandile N, Miller B, Pantoja Munoz L, Peijnenburg WGM, Purchase D, Shevah Y, van Sprang P, Vijver M, Vink JM. 2015. Consideration of the bioavailability of metal/metalloid species in freshwaters: Experiences regarding the implementation of biotic ligand model-based approaches in risk assessment frameworks. Environ Sci Pollut Res 22:7405-7421.

15. European Union. 2008. European Union risk assessment report on zinc and zinc compounds. Final report, Part 1 Environment. Prepared by The Dutch National Institute for Public Health and the Environment (RIVM), on behalf of the European Union, Brussels, Belgium.

16. European Union. 2008. European Union Risk Assessment Report: Nickel and nickel compounds. Prepared by The Danish Environmental Protection Agency, on behalf of the European Union, Brussels, Belgium.

17. European Citizens Initiative. 2008. Voluntary European Union risk assessment report. Copper, copper II sulphate pentahydrate, copper(I) oxide, copper(II)oxide, dicopperchloride trihydroxide. [cited 2016 January 21]. Available from: http://echa.europa.eu/chem_data/ transit_measures/vrar_en.asp

18. European Commission. 2011. Common implementation strategy for the Water Framework Directive (2000/60/EC) guidance document no. 27: Technical guidance for deriving environmental quality standards. Technical Report 2011-055. Brussels, Belgium.

19. European Commission. 2008. Directive 2008/56/EC of the European Parliament and of the Council of 17 June 2008 establishing a framework for community action in the field of marine environmental policy (Marine Strategy Framework Directive). Official J Eur Union L164:19-40.

20. European Union. 2013. Directive 2013/39/EU of the European parliament and of the Council of 12 August 2013 amending Directives 2000/60/EC and 2008/105/EC as regards priority substances in the field of water policy. Official J Eur Union L226:1-17.

21. Verschoor AJ, Vink JPM, Vijver MG. 2012. Simplification of biotic ligand models of $\mathrm{Cu}, \mathrm{Ni}$ and $\mathrm{Zn}$ by one, two and three parameter transfer functions. Integr Environ Assess Manag 8:738-748.

22. De Schamphelaere K, Van Laer L, Deleebeeck N, Muyssen B, Degryse F, Smolders E, Janssen CR. 2006. Nickel speciation and ecotoxicity in European natural surface waters: Development, refinement and validation of bioavailability models. Report prepared for the nickel Producers Environmental Research Association (NiPERA). University of Ghent, Ghent, Belgium.

23. Nys C, Janssen CR, Van Sprang P, De Schamphelaere KAC. 2016. The effect of $\mathrm{pH}$ on chronic aquatic nickel toxicity is dependent on the $\mathrm{pH}$ itself: Extending the chronic nickel bioavailability models. Environ Toxicol Chem 35:1097-1106.

24. Verschoor AJ. 2013. The power of biotic ligand models. Site-specific impact of metals on aquatic communities. $\mathrm{PhD}$ Thesis. Leiden University, Leiden, The Netherlands.

25. Schlekat CE, Van Genderen E, De Schamphelaere KAC, Antunes PMC, Rogevich EC, Stubblefield WA. 2010. Cross-species extrapolation of chronic nickel biotic ligand models. Sci Total Environ 408:6148-6157.

26. Deleebeeck NME, De Schamphelaere KAC, Janssen CR. 2009. Effects of $\mathrm{Mg}^{2+}$ and $\mathrm{H}^{+}$on the toxicity of $\mathrm{Ni}^{2+}$ to unicellular green alga Pseudokirchneriella subcapitata: Model development and validation with surface waters. Sci Total Environ 407:1901-1914.

27. Deleebeeck NME, De Schamphelaere KAC, Janssen C. 2008. A novel method for predicting chronic nickel bioavailability and toxicity to 
Daphnia magna in artificial and natural waters. Environ Toxicol Chem 27:2097-2107.

28. Deleebeeck NME, De Schamphelaere KAC, Janssen CR. 2007. A bioavailability model predicting the toxicity of nickel to rainbow trout (Oncorhynchus mykiss) and fathead minnow (Pimephales promelas) in synthetic and natural waters. Ecotoxicol Environ Saf 67:1-13.

29. Tipping E. 1998. Humic ion-binding model VI: An improved description of the interactions of protons and metal ions with humic substances. Aquat Geochem 4:3-48.

30. National Institute of Standards and Technology. 2004. NIST standard reference database 46, Ver 8.0. Gaithersburg, MD, USA
31. Van Laer L, Smolders E, Degryse F, Janssen C, De Schamphelaere KAC. 2006. Speciation of nickel in surface waters measured with the Donnan membrane technique. Anal Chim Acta 578:195-202.

32. Akaike H. 1981. Likelihood of a model and information criteria J Econom 16:3-14.

33. Peters A, Merrington G, de Schamphelaere K, Delbeke K. 2011. Regulatory consideration of bioavailability for metals: Simplification of input parameters for the chronic copper biotic ligand model. Integr Environ Assess Manag 7:437-444.

34. Peters A, Simpson P, Merrington G, Schlekat C, Rogevich-Garman E. 2014. Assessment of the effects of nickel on benthic macroinvertebrates in the field. Environ Sci Pollut Res 21:193-204. 